\title{
Synchronous occurrence of collagenous colitis and pseudomembranous colitis
}

\author{
Z Vesoulis $\mathrm{MD}^{1}$, G Lozanski MD ${ }^{1}$, T Loiudice $\mathrm{MD}^{2}$
}

Z Vesoulis, G Lozanski, T Loiudice. Synchronous occurrence of collagenous colitis and pseudomembranous colitis. Can J Gastroenterol 2000;14(4):353-358. Synchronous collagenous and pseudomembranous colitis has not been previously reported. A 73-year-old woman presented with chronic watery diarrhea and abdominal cramping of six weeks' duration. Biopsies of the colon revealed findings of collagenous colitis involving the endoscopically normal right colon, and superimposed collagenous and pseudomembranous colitis involving the rectosigmoid colon. Endoscopically, the left colon revealed discrete ulcerative plaques, and Clostridium difficile toxin A assay was positive. The patient partially responded to a three-week regimen of metronidazole, and symptoms resolved completely with subsequent steroid therapy. At follow-up endoscopy four months later, colon biopsies demonstrated persistence of subepithelial collagen but no pseudomembranes. The patient remained asymptomatic during this interval. Collagenous colitis has been reported in association with other inflammatory bowel diseases, including lymphocytic colitis, sprue and idiopathic inflammatory bowel disease. This unique association of collagenous colitis with an endotoxigenic inflammatory bowel disease is presented with a review of related disease features.

Key Words: Collagenous colitis; Pseudomembranous colitis

\section{Présence concomitante de colite collagénique et d'entérocolite muco-membraneuse}

RÉSUMÉ: Jamais des cas de présence concomitante de colite collagénique et d'entérocolite muco-membraneuse n'ont déjà été signalés. Une femme de 73 ans est venue consulter pour diarrhée aqueuse chronique et crampes abdominales depuis six semaines. Les biopsies du côlon ont révélé une colite collagénique dans le côlon ascendant, normal à l'endoscopie, et une colite collagénique et une entérocolite muco-membraneuse dans le côlon recto-sigmoïdien. À l'endoscopie, le côlon descendant présentait des plaques ulcéreuses discrètes, et le dosage de la toxine $\mathrm{A}$ a révélé la présence de Clostridium difficile. La patiente a réagi en partie à un traitement au métronidazole, d'une durée de trois semaines, et les symptômes se sont entièrement résorbés avec un traitement ultérieur aux stéroïdes. Les biopsies du côlon effectuées quatre mois plus tard, à l'endoscopie de contrôle, ont montré une persistance de collagène sous-épithélial, mais aucune pseudomembrane. La patiente n'a présenté aucun symptôme durant cette période. La colite collagénique a déjà été signalée en concomitance avec d'autres maladies intestinales inflammatoires, dont la colite lymphocytaire, la sprue et les entéropathies inflammatoires idiopathiques. Voici un cas unique de colite collagénique associée à une entéropathie inflammatoire endotoxicogène; suit un examen des caractéristiques de maladies apparentées.
$\mathrm{M}$ ore than 100 cases of collagenous colitis have been described in the pathology and gastroenterology literature since the original report by Lindstrom in $1976(1-8)$. The generally accepted histological definition originally required microscopic evidence of subepithelial collagen depo- sition in excess of $10 \mu \mathrm{m}$ in mean thickness (versus a normal mean thickness of 2 to $7 \mu \mathrm{m}$ ). Thickened subepithelial collagen alone is not diagnostic of collagenous colitis because normal rectal mucosa may demonstrate subepithelial collagen that approaches $10 \mu \mathrm{m}$ in thickness. More recently, the

Departments of ${ }^{1}$ Pathology and ${ }^{2}$ Internal Medicine, Summa Health System, Akron, Ohio, USA

Correspondence: Dr Z Vesoulis, Department of Pathology, Akron City Hospital, 525 East Market Street, Akron, Ohio 44304, USA. Telephone 330-375-3902, fax 330-375-4874

Received for publication April 8, 1999. Accepted May 17, 1999 


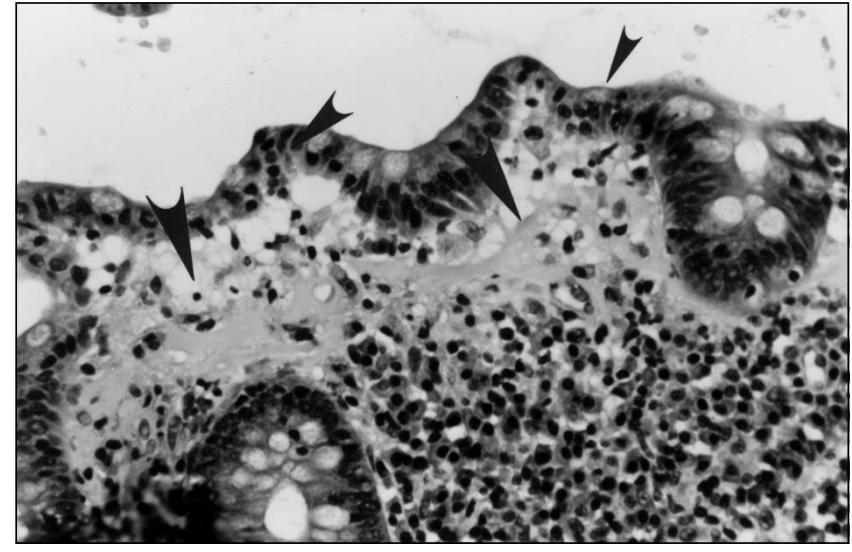

Figure 1) Right colon biopsy with changes diagnostic of collagenous colitis, including a thick layer of subepithelial collagen (large arrowhead), underlying increased chronic inflammatory cell content of the lamina propria and intraepithelial lymphocytes (small arrowhead) (hematoxylin and eosin stain, original magnification $\times 400$ )

definition has been modified to include any 'significant' collagenous thickening associated with a chronic colitis and surface epithelial injury in a patient with chronic, watery diarrhea and an endoscopically normal or 'near normal' mucosa. Other specific causes of diarrhea must be ruled out before confirming a diagnosis of collagenous colitis.

Pseudomembranous colitis, also a chronic diarrheal illness with an often acute explosive onset, has been closely associated with intestinal overgrowth of Clostridium difficile and elaboration of bacterial endotoxins. The etiology, pathological attributes and pathogenetic mechanisms have evolved since its first documentation in 1893, particularly since the inception of widespread antibiotic use in the 1950s (9-11). Collagenous colitis has been reported in association with lymphocytic and/or microscopic colitis, lymphocytic gastritis, Crohn's disease, ulcerative colitis and rheumatic arthritis (12-17). Pseudomembranous colitis has been associated with autoimmune diseases, particularly arthritis $(18-20)$. To our knowledge, there have been no reports of the synchronous occurrence of collagenous and pseudomembranous colitis. One case of resolved pseudomembranous colitis followed by biopsy-proven collagenous colitis has been documented (21).

\section{CASE PRESENTATION}

A 73-year-old white woman presented with a chief complaint of chronic watery diarrhea and lower abdominal cramping without fever. She reported a $6.8 \mathrm{~kg}$ weight loss and eight to 10 bowel movements per day, six weeks in duration. The diarrhea was not alleviated by loperamide. Some episodes of diarrhea were nocturnal. The patient had no previous medical history of protracted diarrhea and no history of arthritis, arthralgia or collagen vascular disease. Pertinent history included gastritis (clinical diagnosis), coronary artery disease and hypertension treated with a daily regimen of cimetidine, nitroglycerin and tenormin, respectively. The patient had taken ampicillin several weeks before the onset of the diarrhea for an unspecified infection. There was no history of nursing home or institutional admissions or stays. The patient required four days of hospitalization with intravenous hydration due to the severity of her presenting diarrheal illness. Stool cultures and examination for ova and parasites were negative, as were duodenal washings for Giardia and the CLOtest (Delta West Ltd, Bentley, Australia) for $\mathrm{H}$ pylori. Stool was positive for the presence of leukocytes and red blood cells. Endoscopic examinations taken during hospitalization revealed discrete ulcerated plaques of the left colon and an endoscopically normal right colon. Stool C difficile toxin A assay by cell culture cytotoxin method and enzyme immunoassay were positive. These results, together with the endoscopy and biopsy findings, prompted treatment with metronidazole (500 mg tid). This treatment was continued for three weeks, with a significant decrease in diarrhea and a follow-up negative $\mathrm{C}$ difficile toxin study. Subsequently, steroid therapy (methylprednisolone $32 \mathrm{mg}$ dose pack) was added; the dose was tapered for two additional months, and symptoms resolved completely. The patient has remained symptom-free for more than a year on mesalamine (400 mg bid). A follow-up examination at four months demonstrated an endoscopically normal colon. Follow-up biopsies of the left and right colon were obtained.

\section{MATERIALS AND METHODS}

Eight endoscopic biopsies from the left colon and rectosigmoid colon were received in $10 \%$ buffered formalin and processed for histological evaluation in the typical manner. Sections were stained with hematoxylin and eosin, and Masson's trichrome. Morphometric measurements of subepithelial collagen in the hematoxylin and eosin-stained sections were carried out using the CAS 200 image analyzer (Becton Dickinson Co, San Jose, California). Mean measurements for each biopsy fragment were determined using Ocular Micrometer version 1.0 software (Cell Analysis Systems, Elmhurst, Illinois). Biopsy fragments with an intact surface epithelium, proper orientation and a continuous uninterrupted zone (at least $200 \mu \mathrm{m}$ in length) of subepithelial collagen were used for measurements. Fragments sectioned tangentially, those with crush or other artifact and those with extensive inflammatory cell infiltrates obliterating the collagenous layer were excluded from measurement. Each of the eight qualified fragments was measured in at least three separate, optimally oriented areas representing the thickest visually determined zones of subepithelial collagen. Each measurement consisted of 10 independent readings at 10 to $20 \mu \mathrm{m}$ intervals. Deposition of thick collagen at each point of measurement was confirmed by correlation with Masson's trichrome staining of parallel sections. An identical technique was used for measurements of subepithelial collagen in the four-month follow-up biopsies.

\section{PATHOLOGY}

Biopsies of the right colon revealed markedly thickened subepithelial collagen in a patchy but widespread distribution in most of the biopsy pieces. This thickened collagen table 


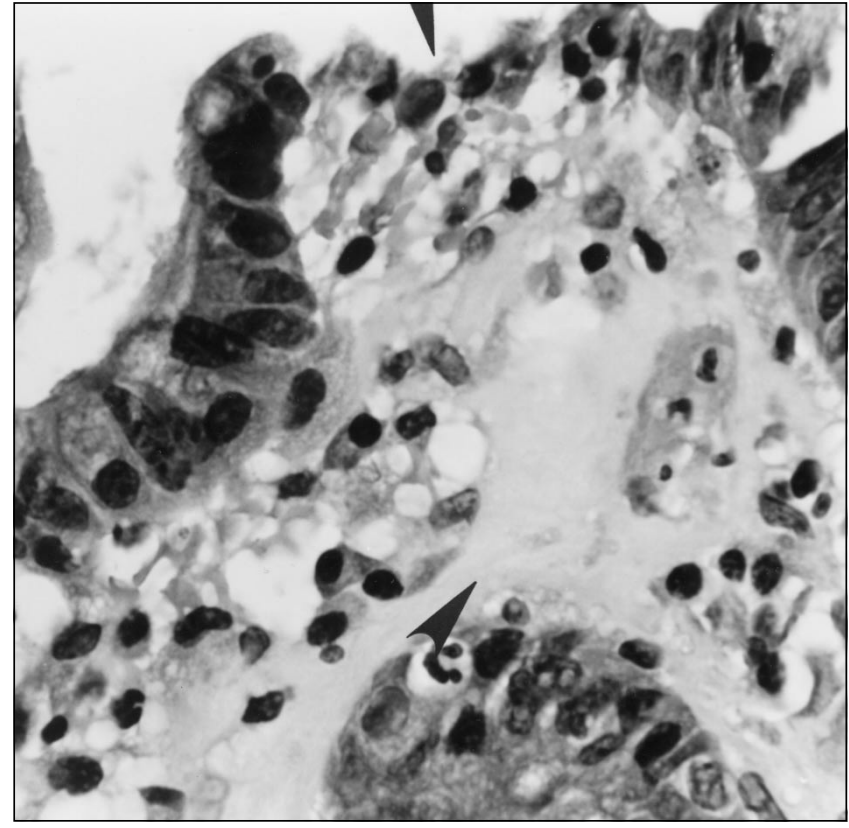

Figure 2) Right colon biopsy showing thick irregular subepithelial collagen (large arrowhead) with vacuolar change and surface epithelial degeneration including vacuolar change (small arrowhead). (hematoxylin and eosin stain, original magnification $\times 400$ )

ranged from 6.7 to $44.4 \mu \mathrm{m}$. The mean thickness of subepithelial collagen in the measured zones was $23.4 \mu \mathrm{m}$. Only well oriented biopsy fragments with at least a $200 \mu \mathrm{m}$ length of uninterrupted collagen were used to maintain objectivity in measurements. The thickened subepithelial collagen was associated with a prominent increase in the inflammatory cell content of the lamina propria, predominantly lymphocytes and plasma cells and including focal eosinophilia and scattered neutrophils with karyorrhectic fragments. Intraepithelial lymphocytes were conspicuous (Figure 1). The superficial colonic epithelium showed extensive degenerative and regenerative changes (Figure 2). Biopsies from the left colon revealed similar markedly thickened subepithelial collagen material, entrapped capillaries with fibrin thrombi and an inflammatory component containing a higher content of neutrophils than that seen in the right colon biopsies (Figure $3)$. Intraepithelial lymphocytes and epithelial degeneration were also identified. In addition, most biopsy fragments from the left colon demonstrated the presence of inflammatory pseudomembranes superimposed on the thickened subepithelial collagen (Figure 4). The pseudomembranes were comprised of fibrin with linear streams of neutrophils and karyorrhectic debris 'erupting' from a degenerated surface epithelium (Figure 5).

Follow-up biopsies of the left and right colon at four months revealed persistence of the thickened subepithelial collagen (range from 6.2 to $42.6 \mu \mathrm{m}$, mean $20.3 \mu \mathrm{m}^{* *}$ ), fewer intraepithelial lymphocytes but no objective decrease in the chronic inflammatory cell content of the lamina propria - persistent collagenous colitis changes. Active inflammatory cells and pseudomembranes were conspicuously absent in the follow-up biopsy (Figure 6).

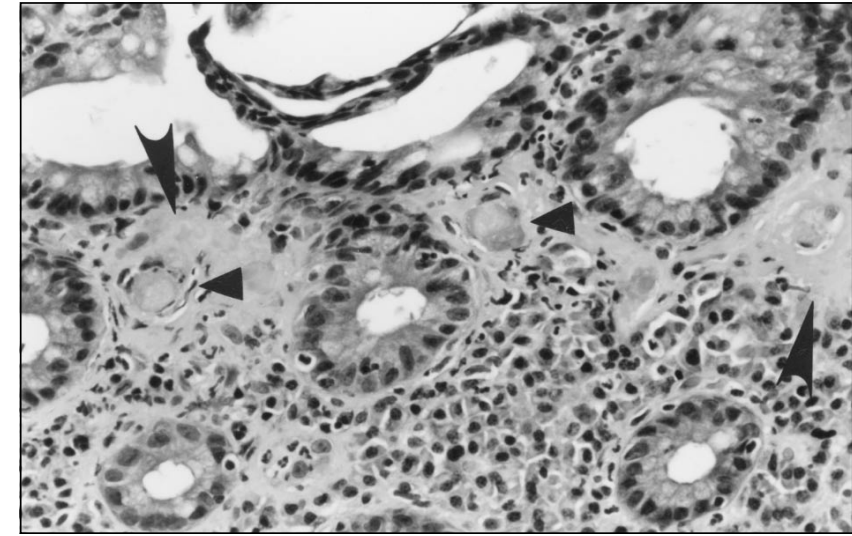

Figure 3) Left colon biopsy with collagenous colitis changes including deposition of subepithelial collagen (large arrowheads), entrapped capillaries with fibrin thrombi (small arrowheads). There is a relative increase in the number of polymorphonuclear cells compared with that seen in right colon biopsies (hematoxylin and eosin stain, original magnification $\times 400$ )

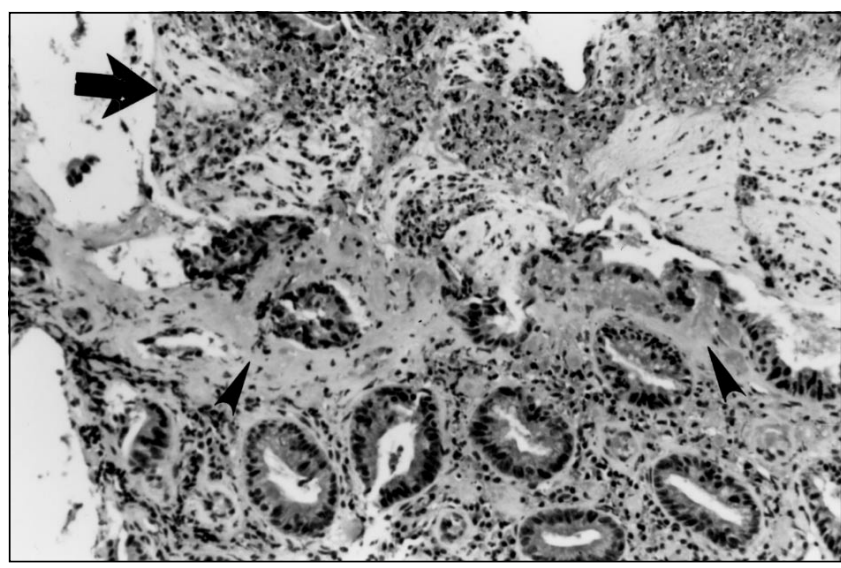

Figure 4) Left colon biopsy showing an inflammatory pseudomembrane comprised of fibrin and neutrophils (arrow) superimposed on irregularly thickened subepithelial collagen (arrowheads) (hematoxylin and eosin stain, original magnification $\times 200$ )

\section{DISCUSSION}

Pseudomembranous colitis has been used descriptively to encompass not only the diarrheal syndrome following antibiotic use, but also any endoscopically or histologically recognized mucosal exudative process. Inflammatory pseudomembranes have been described in ischemic bowel disease, uremia, after irradiation or chemotherapy, and secondary to some bacterial infections, most notably verocytotoxin-producing Escherichia coli O157-H7. It was not until the late 1970s that Price and Davies (22) found that a toxin elaborated by $\mathrm{C}$ difficile was the etiological factor of the antibiotic-associated cases of pseudomembranous colitis. At least four enterotoxins are elaborated by $\mathrm{C}$ difficile, two of which (toxin $A$ and $B$ ) induce mucosal injury. These toxins cause marked permeability in the mucosal epithelial cells and small blood vessels, with resultant fluid and cell loss, causing symptoms of cramping, abdominal pain, watery diarrhea, and findings of blood, fecal blood and leukocytosis. Fe- 


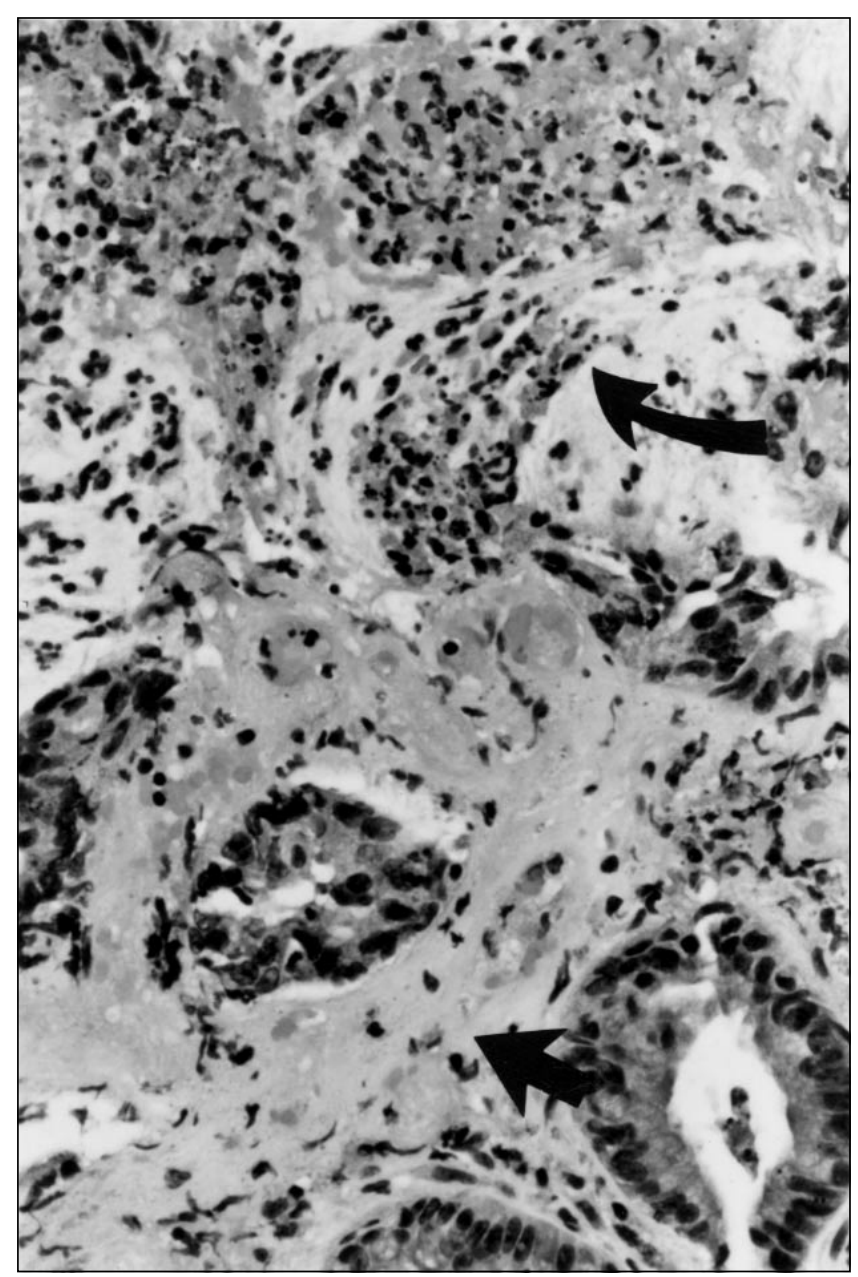

Figure 5) Left colon biopsy inflammatory pseudomembrane with linear streams of neutrophils and karyorrhectic debris in fibrin (curved arrow). Note the thickened subepithelial collagen (arrow) with entrapped capillaries and fibrin thrombi (arrowhead) (hematoxylin and eosin stain, original magnification $\times 400$ )

cal leukocytes, commonly seen in $\mathrm{C}$ difficile and other forms of infectious colitis, have also been described in collagenous colitis $(23,24)$.

Collagenous colitis is a disease with an unknown etiology, poorly understood pathogenesis, irregular colonic distribution, arguable progression and variable, sometimes spontaneous resolution. Lindstrom (6), in his initial report, considered the collagen deposition to be a phenomenon secondary to the chronic inflammatory process that accompanied it. He considered the collagen material to be an anatomical barrier to fluid absorption - thus the watery diarrhea syndrome (6). Others consider the chronic inflammatory process that often coexists with the collagen to be the etiology of the diarrheal disease (25). Direct correlation of lamina propria cellularity and stool weight has been offered as evidence of the importance of the inflammatory component in the pathological process (25).

The relationship of 'microscopic' and lymphocytic colitis with collagenous colitis is not well understood. Some consider these processes to be a continuum, with lymphocytic

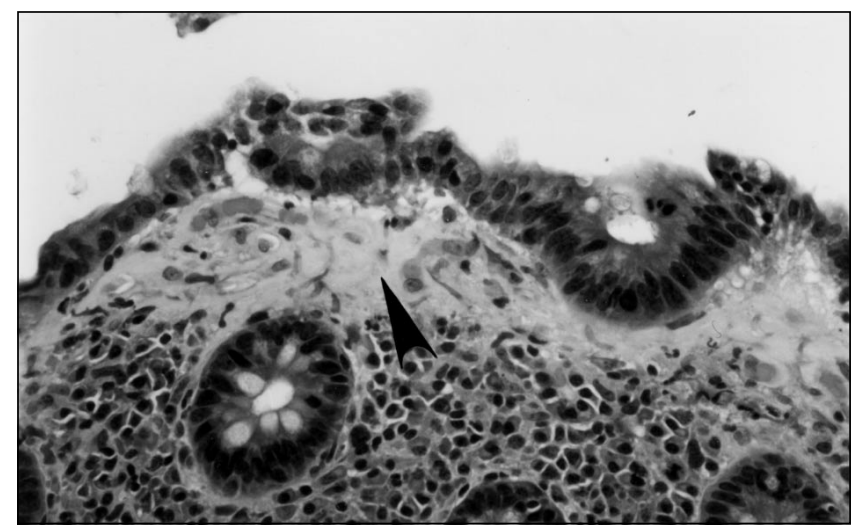

Figure 6) Follow-up biopsy of the left colon at four months reveals persistent subepithelial collagen (arrowhead), chronic inflammation of the lamina propria and complete absence of surface inflammatory pseudomembranes (hematoxylin and eosin stain, original magnification $\times 400)$

colitis being the early manifestation and collagenous colitis being the late manifestation of the same disease. Similar clinical and endoscopic parameters as well as overlapping microscopic features are cited as evidence of a disease continuum $(17,24,26,27)$. As with other forms of inflammatory bowel disease, there is an association of collagenous colitis with autoimmune diseases, thyroid disease, arthritis, celiac disease and idiopathic inflammatory bowel disease. Serum antinuclear antibody is found in up to $50 \%$ of collagenous colitis, as is rheumatoid factor, complement $\mathrm{C} 3$ and $\mathrm{C} 4$, and perinuclear antineutrophilic cytoplasmic antibody (28-32). However, the significance of autoantibodies or elevated serum immunoglobulin levels as an etiological factor in collagenous colitis has not been validated (28). No deposition of immunoglobulin or complement has ever been demonstrated in colonic tissue $(1,26,33)$. Collagenous colitis has been found in association with inflammatory bowel diseases that ostensibly have more convincing evidence of an immunological pathogenesis, including celiac sprue, collagenous sprue, Crohn's disease and ulcerative colitis $(13,16,24,34$ 38). Other proposed etiological factors in the development of collagenous colitis have included bacterial cytotoxins and local toxic factors. Cytotoxic factors have been promulgated in studies of fecal cytotoxic activity after intestinal bypass where collagenous colitis resolved in the bypassed intestinal segment and recurred when the ostomy was closed $(26,39)$. An undesignated bacterial cytotoxin has been demonstrated in collagenous colitis with profound reactivity against McCoy cells in culture but lacking neutralization by $\mathrm{C}$ difficile or Clostridium sordellii antitoxins (26). Cholestyramine, shown to induce resolution of symptoms and histological changes in several described cases of collagenous colitis, is also effective in pseudomembranous colitis. The bile sequestrating resin has a recognized cytotoxin-binding capability $(40,41)$. Likewise, the success of metronidazole and sulphasalazine as antibacterial agents, and their success in the treatment of collagenous colitis suggests a possible infectious etiology (4). Fecal leukocytes have been described in colla- 
genous colitis $(23,42)$ and are commonly seen in pseudomembranous as well as other forms of infectious colitis.

Nonsteroidal anti-inflammatory drugs (NSAIDs) have also been implicated in the pathogenesis of collagenous colitis. Two large studies of patients with collagenous colitis reported NSAID use in $61 \%$ and $71 \%$ of patients, respectively, and resolution of diarrhea in some patients when the drug was discontinued $(3,43)$. NSAIDs have been implicated in a wide range of intestinal pathology, including ischemic lesions, ulcers, bleeding, perforation and collagenous colitis. NSAID injury is believed to be a multistage process, with subcellular organelle damage and nonspecific tissue injury (44).

There is no standard, uniformly effective therapy for collagenous colitis; however, steroids, particularly prednisone, are widely believed to be the most effective therapy. Other drugs used with success include 5-aminosalicylate, sulphasalazine, azathioprine and methotrexate; locally active steroids

\section{REFERENCES}

1. Giardiello FM, Bayless TM, Jesserun J, Hamilton SR, Yardley JA. Collagenous colitis: physiological and histopathologic studies in seven patients. Ann Intern Med 1989;106:46-9.

2. Gledhill A, Cole FM. Significance of basement membrane thickening in the human colon. Gut 1984:25:1085-8.

3. Goff JS, Barnett JL, Pelke T, Appleman HD. Collagenous colitis: Histopathology and clinical course. Am J Gastroenterol 1997;92:57-60.

4. Jesserun J, Yardley JH, Giardiello FM, Hamilton SR, Bayless TM. Chronic colitis with thickening of the subepithelial collagen layer (collagenous colitis): Histopathologic findings in 15 patients. Hum Pathol 1987;18:839-48.

5. Lazenby AJ, Yardley JH, Giardiello FM, Bayless TM. Pitfalls in the diagnosis of collagenous colitis: Experience with 75 cases from a registry of collagenous colitis at the Johns Hopkins Hospital. Hum Pathol 1990;21:905-10.

6. Lindstrom CG. Collagenous colitis with watery diarrhea A new entity? Pathol Eur 1976;11:87-9.

7. Rams H, Rogers AI, Ghandur-Mnaymneh L. Collagenous colitis. Ann Intern Med 1987;106:108-13.

8. Widgren S, Jlidi R, Cox JN. Collagenous colitis: Histologic, morphometric, immunohistochemical, and ultrastructural studies. Report of 21 cases. Virch Archiv A Pathol Anat Histopathol 1988;413:287-96.

9. Klatz AP, Palmer WL, Kirsner JB. Aureomycin roctitis and colitis; A report of five cases. Gastroenterology 1953;25:44-4.

10. O'Conner TW. Pseudomembranous enterocolitis: A historical and clinical review. Dis Colon Rectum 1981;24:445-8

11. Reiner L, Schlesinger MJ, Miller GM. Pseudomembranous colitis following aureomycin and chloramphericol. Arch Pathol 1952;54:39-67.

12. Bohr J, Tysk C, Eriksson S, Abrahamsson H, Jarnerot G. Collagenous colitis: A retrospective study of clinical presentation and treatment in 163 patients. Gut 1996;39:846-51.

13. Chandratre S, Bramble ME, Cooke WM, Jones RA. Simultaneous occurrence of collagenous colitis and Crohn's disease. Digestion 1987;36:55-60.

14. Christ AD, Meier R, Bauerfiend P, Wegmann W, Gyr K. [Simultaneous ccurrence of lymphocytic gastritis and lymphocytic colitis with transition to collagenous colitis]. Schweiz Med Wochenschr 1993;123:1487-90.

15. Geboes K. Collagenous and microscopic colitis: Clinical importance. Neth J Med 1994:45:47-51

16. Giardiello FM, Jackson FW, Lazenby AJ. Metachronous occurrence of collagenous colitis and ulcerative colitis. Gut 1991;32:447-9.

17. Lazenby AJ, Yardley JH, Giardiello FM, Jessurun J, Bayless TM. Lymphocytic (microscopic) colitis: A comparative histopathologic study with particular reference to collagenous colitis. Hum Pathol 1989;20:18-28. such as budesonide have been advocated in patients refractory to prednisone $(3,45-47)$. Efficacy of these therapies is difficult to verify because collagenous colitis often undergoes spontaneous regression of symptoms and histopathological lesions .

A direct relationship between pseudomembranous and collagenous colitis cannot be extrapolated from the findings in this report; their simultaneous occurrence in this patient may be coincidental. However, as described, intriguing overlapping clinical and pathological features may implicate an infectious or cytotoxic basis for collagenous colitis as well as pseudomembranous colitis. The superimposition of histological and clinical findings of collagenous and pseudomembranous colitis has not been previously described, but as with other previously unrelated colitides and diarrheal syndromes, further understanding of the pathogenesis and related clinical syndromes may eventually demonstrate some association.

18. Atkinson $\mathrm{MH}, \mathrm{McCleod} \mathrm{BD}$. Reactive arthritis associated with C. difficile enteritis. J Rheumatol 1988;15:520-2.

19. Rollins D, Moeller D. Acute migratory polyarthritis associated with antibiotic induced pseudomembranous colitis. Am J Gastroenterol 1976;65:353-6.

20. Lofgren RP, Tadlock LM, Solitis RD. Acute oligoarthritis associated with Clostridium difficile pseudomembranous colitis. Arch Intern Med 1984;144:617-9

21. Giardiello FM, Hansen FC, Lazenby AJ, et al. Collagenous colitis in the setting of non-steroidal anti-inflammatory drugs and antibiotics. Dig Dis Sci 1990;35:257-60.

22. Price AB, Davies DR. Pseudomembranous colitis. J Clin Pathol 1977;30:1-12.

23. Lawson JM, Wolosin J, Mottet MD, Brower RA. Collagenous colitis: An association with fecal leukocytes. J Clin Gastroenterol 1988;10:672-5.

24. Zins BJ, Sandborn WJ, Tremaine WJ. Collagenous and lymphocytic colitis: Subject review and therapeutic alternatives. Am J Gastroenterol 1995;90:1394-400.

25. Lee E, Schiller LR, Vendrell D, Santa Ana CA, Fordtron JS. Subepithelial collagen table thickness in colon specimens from patients with microscopic and collagenous colitis. Gastroenterology 1992;103:1790-6.

26. Anderson T, Andersen Jr, Tvede M, Franzman MB. Collagenous colitis: Are bacterial cytotoxins responsible? Am J Gastroenterol 1993;88:375-7.

27. Jesserun J, Yardley TH, Lee EL, Vandrell DD, Schiller LR, Fordtran JS. Microscopic and collagenous colitis: Different names for the same condition? Gastroenterology 1986;91:1583-4. (Lett)

28. Bohr J, Tysk C, Yang P, Danielsson D, Jarnerot G. Autoantibodies and immunoglobulins in collagenous colitis. Gut 1996;39:73-6.

29. Duerr RH, Targan SR, Landers, CJ, Sutherland TR, Shanahan F. Antineutrophil cytoplasmic antibodies in ulcerative colitis. Comparision with other colitides/diarrheal illnesses. Gastroenterology 1992;100:1590-6.

30. Roubernoff R, Ratain J, Giordiello F, et al. Collagenous colitis, enteropathic arthritis and autoimmune diseases: Results of a patient survey. J Rheumatol 1989;16:1229-32.

31. Sylwestrowicz T, Kelley JK, Hwang WS, Shaffer EA. Collagenous colitis and microscopic colitis: The watery diarrhea-colitis syndrome. Am J Gastroenterol 1989;84:763-8.

32. Van Tilburg AJ, Lam HG, Sedlenrijk CA, et al. Familial occurrence of collagenous colitis. A report of 2 families. J Clin Gastroenterol 1990;12:279-85

33. Farah DA, Mills PR, Lee FD, McLay A, Russell RI. Collagenous colitis: Possible response to sulfasalazine and local steroid therapy. Gastroenterology 1985;88:792-7.

34. Armes J, Gee DC, Macrae FA, Schroeder W, Bhathal PS. Collagenous colitis: Jejunal and colorectal pathology. J Clin Pathol 1992;45:784-7. 
35. Eckstein RP, Dowsett JF, Riley JW. Collagenous enterocolitis: A case of collagenous colitis with involvement of the small intestine. Am J Gastroenterol 1988;83:767-71.

36. Hamilton I, Sanders S, Hopwood D, Bouchier IA. Collagenous colitis associated with small intestinal villous atrophy. Gut 1986;27:1394-8.

37. McCashland TM, Donovan JP, Strobach RS, Linder J, Quigley EM. Collagenous enterocolitis, A manifestation of gluten sensitive enteropathy. J Clin Gastroenterol 1992;15:45-51.

38. O'Mahony S, Nawroz IM, Ferguson A. Celiac disease and collagenous colitis. Postgrad Med J 1990;66:238-41.

39. Jarnerot G, Tysk C, Bohr J, Eriksson S. Collagenous colitis and fecal stream diversion. Gastroenterology 1995;109:449-455.

40. Kreutzer EW, Milligan FD. Treatment of antibiotic-associated pseudomembranous colitis with cholestyramine resin. Johns Hopkins Med J 1978;143:67-72.

41. Taylor NS, Bartlett JG. Binding of C. difficile cytotoxin and vancomycin by anion exchange resins. J Infect Dis 1980;141:92-7.
42. Zins BJ, Tremaine WJ, Carpenter HA. Collagenous colitis: Mucosal biopsies and association with fecal leukocytes. Mayo Clin Proc 1995;70:430-3.

43. Riddell RH, Tanaka M, Mazzoleni G. Nonsteroidal anti-inflammatory drugs as a possible cause of collagenous colitis: a case control study. Gut 1992;33:683-6.

44. Bjarnason I, Hyllor J, MacPherson AJ, Russell AS. Side effects of nonsteroidal anti-inflammatory drugs on the small and large intestine in humans. Gastroenterology 1993;104:1832-47.

45. Lanyi B, Dries V, Dienes HP, Kruis W. Therapy of prednisone refractory collagenous colitis with budesonide. Int J Colorectal Dis 1999;14:58-61.

46. Delarive J, Saraga E, Dorta G, Blum A. Budesonide in the treatment of collagenous colitis. Digestion 1998;59:364-6

47. Pimentel RR, Achkar E, Bedford R. Collagenous colitis. A treatable disease with an elusive diagnosis. Dig Dis Sci $1995 ; 40 ; 1400-4$. 


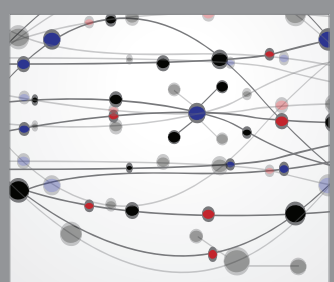

The Scientific World Journal
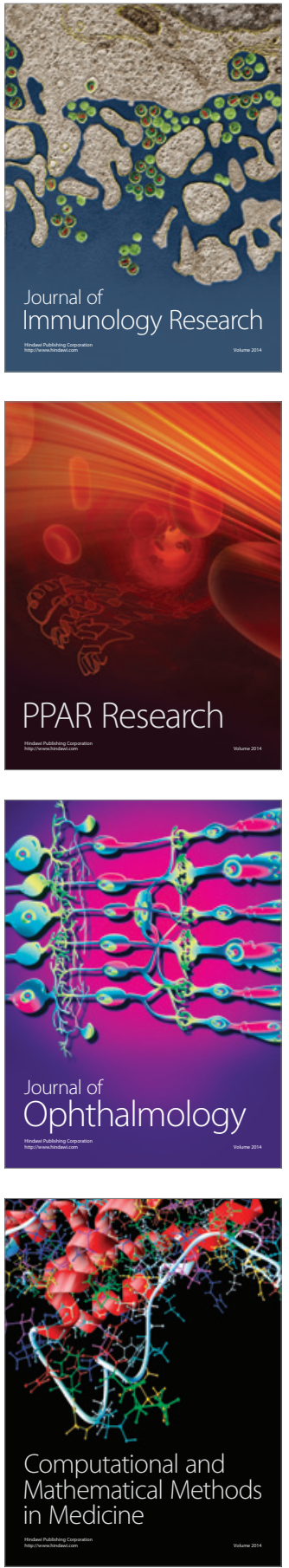

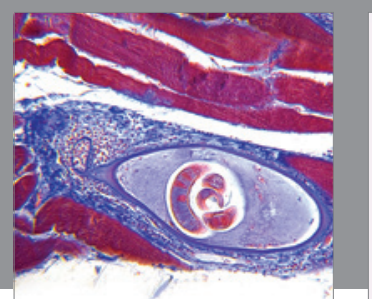

Gastroenterology Research and Practice

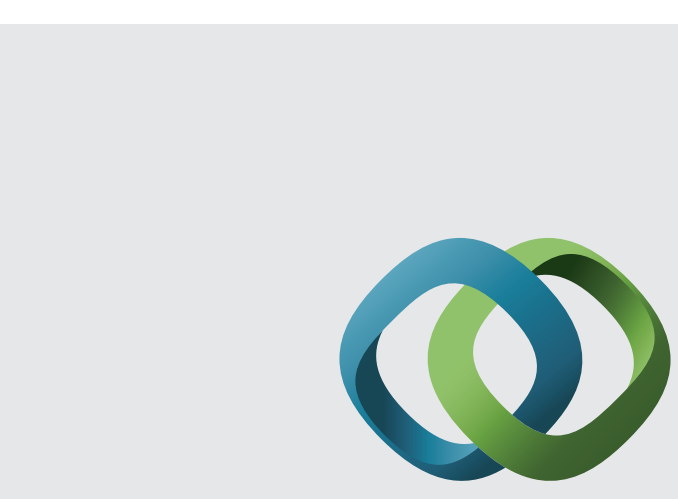

\section{Hindawi}

Submit your manuscripts at

http://www.hindawi.com
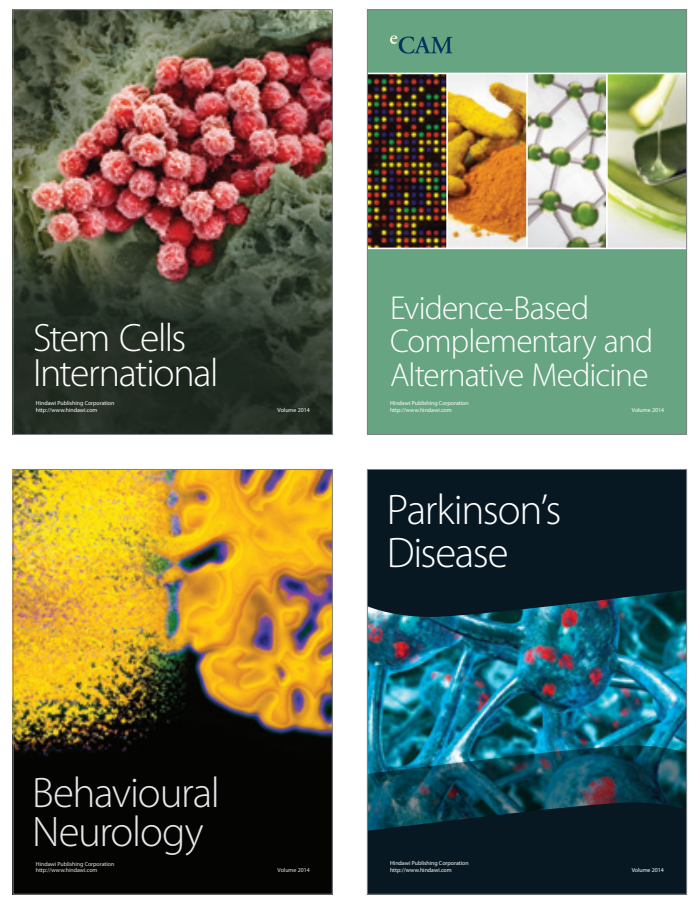
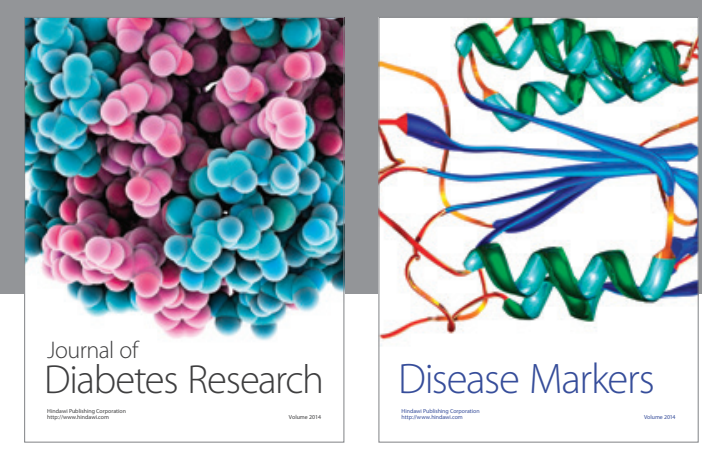

Disease Markers
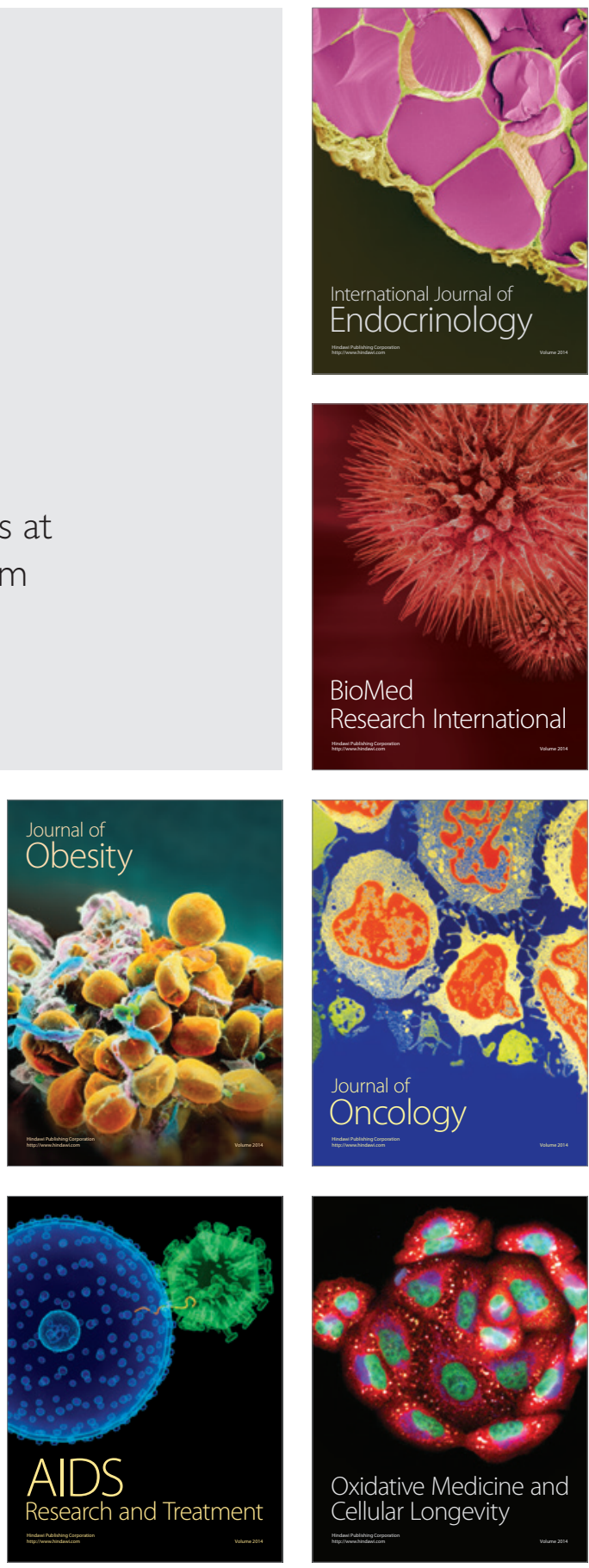